\title{
Integration of Literature in English Language Teaching: Learners' Attitudes and Opinions
}

\author{
Sami Hussein Hakeem Barzani ${ }^{1} \&$ Reman Sabah Meena ${ }^{2} \&$ Hewa Fouad Ali ${ }^{3}$ \\ ${ }^{1,2,3}$ English Language Teaching Department, Tishk International University, Iraq \\ Correspondence: Sami Hussein Hakeem Barzani, Tishk International University, Iraq \\ Email: sami.hussein@tiu.edu.iq
}

DOI: $10.53103 /$ cjlls.v1i1.12

\begin{abstract}
Speaking of the role and position of literature in language teaching platforms, generally, two opposite views are in action, namely essentialist and non-essentialist. However, numerous studies have stressed the influential role of literature. This study investigated the opinions and preferences of EFL university students on the integration of literature in English language learning. To do so, a mixed-method research design was utilized in which data were collected quantitively through a 12 items questionnaire and qualitatively using five open-ended questions. The quantitative data were analysed using SPSS, whereas descriptions were used to analyse the qualitative data. For the quantitative part, $30 \mathrm{EFL}$ students and for the qualitative phase, $10 \mathrm{EFL}$ students participated. The findings indicated that students consider literature as a significant tool for learning English language and enhancing the four main language skills. It is also discovered that students find literary texts to develop awareness of cultural knowledge, which is inseparable in learning a second language. In a nutshell, the findings discovered that students showed positive attitudes toward using literature in learning English as a foreign language.
\end{abstract}

Keywords: Literature, Literary texts, Attitudes and Opinions

\section{Introduction}

A language is a crucial tool in human beings' life. Language plays a crucial role in many ways, namely enhancing daily life communication, completion of business transactions, more importantly, in the transfer of knowledge and many more (Barzani, 2020). Thus, through language use, an individual masters and operate a host of life services. In this line, as a popular language, English has been applicable and received the most attention and load in the usage of different professions and spheres of life. It can be said that English, due to its spread and common use for various purposes, is considered the sole language of the globe. Therefore, almost everywhere in the globe, English has been a part, if not the medium, of the education system. To teach English successfully, many approaches and methods have been in use. Besides those approaches and techniques, various ways and the inclusion of different materials have been used. Yet, it should be stated that, as its nature, language is a two way of communication. In other words, for successful and meaningful communication, both spoken and comprehension abilities must be met. 
Nowadays, English second/foreign language (EFL/ESL) teachers are beginning to incorporate more communicative approaches. This new perspective makes learners more independent and more conscious of their learning process and allows them to think logically and critically. Regarding this, the inclusion of literature in the curricula has been a subject of interest to many EFL/ESL teachers, educators and researchers. (Susan Louise Stern, 1985; Yorio, 1971; Mckinley, 1974; Walsleben, 1975; Gorman, 1979; \& Povey, 1979, Barzani, 2020) all attested to the effectiveness of literature in second language learning.

Speaking of the role and position of literature in language teaching platforms, generally, two opposite views are in action, namely essentialist and non-essentialist (Edmondson, 1997; Scott \& Tucker, 2002; Donato \& Brooks, 2004; Yuksel, 2007). The non-essentialist proponents attach little or sometimes no value to literature in language teaching and learning. According to Claudia Ferradas (2009), literature "contains insufficient practical application, it is regularly narrowly associated with a specific cultural context, and it can be personal, even subversive" (p. 27). On the other hand, the essentialist supporters and a growing body of research consider literature as a must and effective in the aforementioned process. That is, the incorporation of literature would enhance language competence (Lazar, 1993; McKay, 1982; Widdowson, 1984), cultural awareness (Akyel \& Yalcin, 1990; Ghosn, 2002; Lazar, 1993, 1994; McKay, 1982; Parkinson \& Thomas, 2000; Shanahan, 1997), critical thinking (Ghosn, 2002; Lazar, 1993; Parkinson \& Thomas, 2000), and motivation (Akyel \& Yalcin, 1990; Ghosn, 2002; Lazar, 1993; McKay, 1982; Parkinson \& Thomas, 2000) in a second/foreign language context.

In this line, the introduction of literary texts in developing a second language has been acknowledged in the last decade by many English language teaching professionals for its numerous benefits, as well as being an innovative way for students to learn the language more naturally (Littlewood 2000, cited in Handayani, 2013). Similarly, scholars, such as Rew and Moon (2013), have noted that the utility of literary materials have the capacity to trigger learners to share ideas within a classroom context while deriving a link between the text and real-life contexts. In addition, A'shour \& Magdadi (2005) (as cited in Sallal, 2014) suggests that literary texts are identified as the most provocative and motivational elements in language learning and improvement; they are sources of natural interaction that increases learners focus on the events and meanings. More importantly, such materials tend to be repetitive in nature, enabling learners to be familiar with syntactical aspects, as well as consolidating certain vocabulary items and building predicting skills extensively. The learners, in fact, start to develop a lexicon, memorizing and then reciting and chanting these forms. Literature also is known to reinforce as Taylor (2000) emphasizes cognitive and academic skills, which will be needed every time the learner reads.

However, despite the above-mentioned advantages, the inclusion of literature is not challenge-free for a teacher. The most obvious hesitation teachers face is the selection of literary texts due to their difficulty, linguistic richness, students' interaction and interest, and cultural issues that might be sensitive to some. Therefore, selecting 
suitable literary texts is the principal teaching phase in ESL/EFL contexts. Similarly, to overcome such issues, researchers suggest various methods. The one made by Lazar (1993) is one of the most widely held classifications of approaches to the use of literature in English language teaching classrooms. She advises first defining the needs of students, and then adapting the most fitting model accordingly. Three methods, namely the language-based model, literature as material and literature as personal enrichment, are stated in her model.

a. Language-based model: These models suggest the use of syllabuses made of the incorporation of language and literature, which stresses the use of concepts of grammar, lexis, and discourse to allow an artistic analysis of literary texts.

b. Literature as content: Literature is the fundamental course element of this approach. Literary texts are studied in terms of their historical and cultural contexts, genres, and rhetorical instruments.

c. Literature for personal enrichment: This technique offers students an ability to focus on their personal perspectives, beliefs, and emotions. The fundamental prompts for the classroom operations are texts.

This research, keeping in mind the advantages and effectiveness of literature and its inclusion in the EFL classrooms, attempts to investigate the views of Kurdish EFL learners regarding the use and effectiveness of literature (literary texts) in the enhancement of English language learning. To do so, the present study endeavours to address the following research questions:

1. What are the preferences and attitudes of Kurdish EFL university students toward the use of literature in an English language learning setting?

2. Do literary materials assist the development of different areas of language skills?

3. Is there any significant impact of literary texts on learner's recognition of different sentence pattern types?

\section{Statement of the Problem}

As a foreign language in many places of the world, English is a main subject of schooling. Likewise, in the Iraqi Kurdistan Region, it is a subject taught from primary school up to four years of university. However, despite all these years of studying English, the majority of them worldwide face difficulties of expression or are not well enabled with a good command of communication in real-life situations. This is due to a number of factors, including: physiological reasons related to the student's motivation and their will toward learning English; the teaching factors associated with the methods and materials used in the teaching process. A massive amount of research indicates that the inclusion of literature has a positive impact on the improvement of English language skills as well as it develops their motivation and awareness, enhances their awareness of cultural language-related issues, and improves the identification and 
reproduction of sounds for a correct pronunciation (Barzani, 2020). However, this works best when learners have positive attitudes toward such literary texts. Thus, this study is an attempt at figuring out the preferences of Kurdish EFL learners toward the use of literature on the development of English language competence.

\section{Significance of the Study}

Each study should address a problem, and its conclusion should provide some solutions to the addressed issue. The significance of the present study would occur from the importance of the research problem. This significance can be concluded in the following points.

1. The present study's findings might offer EFL/ESL teachers valuable information and enrich their knowledge to improve students' English competence.

2. It is aimed that the study results will help teachers reconsider their syllabus and teaching materials.

3. The students can develop their English language skills using literary texts as they would be offered with knowledge of the importance of literature in developing English language skills.

\section{Literature Review}

The use of literature in class is among the various approved ways which instructors use to improve different areas of English language learners. Today, educational institutions have resorted to seeking ways of resolving learner needs regarding difficulties learners might face during the process (Elhaj, 2017). The use of literary texts as a strategy to enhance English language learning can be traced to the $19^{\text {th }}$ century, during which literary forms were utilized as a major tool for the Grammar Translation Method. Learners were required to translate literary texts into their native languages. The relevance of this approach can be heavily borrowed from the current study as the learners were only expected to focus on surface levels like the meaning assigned to grammatical structures or given vocabulary as opposed to the literary value of such forms (Elhaj, 2017). With reference to findings in the literature, this section provides the various justifications for the use of literature as a tool for enhancing English language teaching.

\section{Where Does Literature Locate in ELT?}

Back in the 1950s and to the beginning of the 1980s, English language teaching was mainly occupied by communicative functions of language. The main concerns were communicative competence and specific practical and functional purposes. Methods concentrated on using language in public circumstances, and syllabuses were planned along 'functional/notional lines' (Brumfit, 1985 p. 6). Creativity and literature 
were given little, almost none, space in such language teaching frameworks (Lima 2010, p.110).

However, the 1980s experienced a remarkable shift in the process of English language teaching. The inclusion of literature in the teaching of English was highly considered. Numerous scholars state that literature has shaped a new and striking setting in which literary texts have never been so widely regarded as one of the most important resources available in EFL classrooms before (Thom 2008, p.120). Following this, things started to improve in the last decades of the twentieth and the beginning of the twenty-first century. Literature started to be used as a possible source of language development (Hall, 2005), possibly due to the opinion that abandoning such a rich source of language input was something wrong (Lima, 2010, p.110). All in all, regardless of the two conflicting positions toward the use and place of literature mentioned earlier (essentialist and non-essentialist), literary materials have found their place in the language teaching contexts and are used widely.

\section{Literary Materials' Impact on Language Skills Development}

Long ago, it has been pointed out that literary texts have a myriad of benefits. This is to say, the use of such materials leads to the reinforcement of the four main English languages, namely listening, speaking, reading, and writing (Erkaya, 2003). Such texts offer learners the opportunity to enhance their listening skills or even the chance to read aloud, which means that learners can learn the correct accents and pronunciations. An instructor may further request learners to role-play in front of their peers, which in turn develops the learners' speaking skills (Erkaya, 2003). Literary materials, through the four skills, develop the vocabulary of the learners. For instance, a teacher assigns a learner to pre-determined activities like matching acronyms and words, on the insertion of novel words to complete sentences. This forces learners to read a story, comprehend its events, thereby developing their reading comprehension skills (Erkaya, 2003).

\section{Literary Materials and Triggering of Learner Motivation}

Knowledge is developing gradually, and the consequences of this improvement are reflected in education as well as in many areas. This progress affects the world's needs and changes the roles of students, teachers, and parents in motivation and helping learners achieve more in their learning journey. This change is reflected in the education programs, ensuring that individuals are raised as individuals who adapt to the conditions of the day and respond to their needs.

Until the beginning of the last century, learning was regarded as an act performed by individuals sitting in a certain order in a classroom, listening to the teacher, who was the authority of the lesson, taking note of what was told, and answering questions. Political, social and economic changes that took place in the world in the same century 
naturally affected the education systems, and there were also changes in perceptions about education and learning.

Undoubtedly, one of the most influential factors in learning a second language is motivation. Notably, the structure and content of literary texts help to trigger and install this important factor in students. Studies show that literary products have a positive effect on student success, attitude and behaviour. Literary products contribute to children's language, reading-writing, empathy and communication skills; in the same vein, they have a positive effect on the development of universal and national values in students (Akkus, 2007, p.127-128). Since literary works improve students' thinking skills, the knowledge acquired in this way becomes permanent. Literary products increase students' interest in the lesson. They are a very effective way to provide the purposes such as gaining a reading habit, establishing relationships between subjects and stimulating what has been learned (Tekgöz, 2005, p.90).

Students who develop language skills through literary products will also gain basic thinking skills, as they can easily develop themselves on words and conceptual perceptions, which are the building blocks of thought.

The finding of many studies has shown that the use of literary materials in language learning classrooms has a positive effect on students' academic success and increases the permanence of the learned knowledge. This notion overlaps with the study's findings conducted by Davis and Palmer (1992) on the same subject because Davis and Palmer (1992) concluded in their related research that literary materials increase learners' achievement and success.

\section{Promotes Higher Order Learning}

The third role is promoting higher-order thinking. Literary texts, namely short stories may force learners to analyse the content of the stories and think critically, which impacts developing higher-order thinking skills. Indeed, Erkaya (2003) notes that such materials are tied to two major benefits; they are highly interesting to learners as they introduce learners to aspects of critical thinking; and as they demand higherorder thinking, they are often more memorable to the learners. Thus, the role of the teacher is to ensure that learners get the necessary help to enhance their higher-order thinking (Bloom, 1956). Thus, the instructor can achieve through requesting learners to derive judgments, make assessments, apply knowledge, create new ideas, and organize information (Bloom, 1956). The Blooms Domain aspects of the lower and higher-order thinking come into play in this sense. Here, the instructor is expected to come up with the thinking skill they desire their learners to master. For a beginner, for instance, it is necessary that the teacher test the learners' ability to recall information, including the ability to state the character's names in short stories; a level identified as knowledge (Sultan, Nafi, Qabaja, \& Al-abed, 2018). Upon successful completion of this level, the learners may move to the next higher comprehension level in which the learners are tasked to compare the characters. The third application level may demand that the learners to exhibit their language comprehension proficiency through 
resolution of problems in literary texts (Sultan, Nafi, Qabaja, \& Al-abed, 2018). The fourth level is analysis in which learners ought to exhibit intermediate proficiency level where they analyse the events occurring in the texts. The synthesis level entails advanced proficiency in a language, in which learners can synthesize any given literary materials (Sultan, Nafi, Qabaja, \& Al-abed, 2018). The evaluation level marks the highest reading comprehension level in which learners have the capacity to evaluate read content. For instance, such learners may respond to and defend their positions on whether or not they agree with the events that unfold in the stories (Sultan, Nafi, Qabaja, \& Al-abed, 2018).

\section{Literature Teaches about Cultural Diversity}

Language and culture are inseparable. Culture plays a very important role in the teaching process of a second language. Many scholars and language educators claim that when language is learnt stripped from culture, it creates speakers that do not understand the "language in social and philosophical content" even though they may be fluent (Mahmoud, 2015, p.68). To master a second language well, it requires a good knowledge of culture. This is due to that language is highly culturally loaded (Barzani, 2020). For these reasons, literature is considered to assist in the comprehension of cultural issues. Undoubtedly, literature is culture-specific: the experience of being introduced to literary texts enables learners to access the unknown territory of the world of the target language in order to become familiar with the various aspects of its lifestyle like its customs, possessions, as well as portraying certain and essential human issues, making the learning process more effective and beneficial. (Collie \& Slater, 2005; O'Connell, 2009). Moreover, in the context of learning English as a foreign language, literary materials effectively transmit the cultures of people (Barzani, 2020). Indeed, critics such as Newton et al. (2018) argue that when literary texts are appropriately identified, selected, and utilized, and they carry the potential to offer quality text content that can improve ELT courses and cultural awareness of learners.

\section{Enhances Self-Dependency in Foreign Language Learning}

Elhaj (2017) undertakes a review of Carter and Brumfit's recommendations for using literature for an effective foreign language skill teaching. Such review reveals that literary texts offer a practical session for English language teachers owing to their ample length and richness as a single text may last a lesson or two. In addition, these texts are void of complexity; thus, learners may work on their own, which is necessary for developing the learners' self-dependency in learning a second foreign language (Kilfoil \& Van, 2003). Literary texts are born of an artist's creativity (Elhaj, 2017). Such writers are linked with mastery of language, and their products often make an ideal resource for improving reading comprehension skills. For this reason, Elhaj (2017) recommends that foreign language teachers rely on literary materials as an 
effective tool for the development of reading comprehension, as well as other skills for their learners.

\section{Enhances Reading Comprehension Skills Integration}

Effective use of literary materials may offer the teacher the opportunity to integrate reading comprehension skills with other essential skills, including writing and speaking (Khatib \& Nasrollahi, 2012). In addition, if such materials happen to have elements of actual natural dialogue scenarios, the learners might have an opportunity to familiarize themselves with authentic, functional use of daily language (Khatib \& Nasrollahi, 2012). Equally, the instructors may find such excerpts helpful in arresting the attention and interest of learners, which is an important ingredient for reading comprehension skill development.

\section{Methodology \\ Data Collection Instruments and Analysis}

To address and achieve the purpose of the study, a mixed-method research design was utilized in which both quantitative and qualitative means of data collection were used. The rationale behind the employment of such a method was its appropriateness and strength in uncovering the in-depth attitudes and preferences of Kurdish EFL learners. To do so, quantitative data were collected using 12 item questionnaires, and qualitative data were attained using semi-structured interviews via six open-ended questions. As to the data analysis, quantitative data were analysed using SPSS, whereas descriptive analysis was carried out to analyse the qualitative data.

\section{Participants and Setting}

The study used two instruments for eliciting learners' preferences and opinions concerning the use of literature in learning English, therefore for the quantitative phase, 30 Kurdish EFL university students participated. In contrast, in the qualitative phase, ten students were interviewed. The participants were third and fourth graders in the English Language Teaching department at Tishik International University, Kurdistan Region-Iraq.

\section{Results and Discussions Quantitative Findings}

This part undertakes an analysis of the data collected quantitatively through the use of questionnaires. The Chi-square value test assessment is offered for the research question-derived hypotheses. The results from SPSS analyses are presented in tabular form following a brief explanation. 


\section{First Research Question Validation}

Table 1: First hypothesis percentage and frequencies

\begin{tabular}{llllll}
\hline Statements & $\begin{array}{l}\text { Strongly } \\
\text { Agree }\end{array}$ & Agree & Neutral & Disagree & $\begin{array}{l}\text { Strongly } \\
\text { Disagree }\end{array}$ \\
\hline $\begin{array}{l}\text { Literary texts are helpful in } \\
\text { learning more vocabulary in } \\
\text { the form of new words used }\end{array}$ & 27 & 2 & - & - & 1 \\
in variant contexts & $90.0 \%$ & $6.7 \%$ & - & - & $3.3 \%$ \\
$\begin{array}{l}\text { Literature develops my } \\
\text { reading skills }\end{array}$ & 23 & 5 & 1 & & 1 \\
& $76.7 \%$ & $16.7 \%$ & $3.3 \%$ & - & $3.3 \%$ \\
$\begin{array}{l}\text { Literary texts help recognize } \\
\text { grammatical sentence build- } \\
\text { up }\end{array}$ & 16 & 9 & 5 & - & - \\
$\begin{array}{l}\text { Exposure to literary texts } \\
\text { enhances my different article } \\
\text { reading speed }\end{array}$ & 19 & 9 & 1 & 1 & - \\
& $63.3 \%$ & $30.0 \%$ & $16.7 \%$ & - & - \\
\hline
\end{tabular}

Table 1 shows that 27 respondents strongly agree (90\%), 2 agree (6.7\%), while only 1 strongly disagrees (3.3\%) that literary texts help in enhancing vocabulary. The table shows that 23 respondents strongly agree (76.7\%), 5 agree (16.7\%), 1 neutral $(3.3 \%)$, and 1 strongly disagree $(3.3 \%)$ that literature helps them to develop their reading skills. Further, 16 strongly agree (53.3\%), 9 agree $(30.0 \%)$, and 5 are neutral (16.7\%) that such texts help them recognize the different sentence patterns. Lastly, the analysis indicates that 19 strongly agree (63.3\%), 9 agree (30.0\%), 1 neutral (3.3\%), and 1 strongly disagrees $(3.3 \%)$ that increased readership of literary texts increases the speed of reading different texts.

First Research Question Descriptive Analysis 
Table 2: First Hypothesis Descriptive Analysis

\begin{tabular}{lccc}
\hline Statements & Mean & Mode & $\begin{array}{l}\text { Std. } \\
\text { Deviation }\end{array}$ \\
\hline $\begin{array}{l}\text { Literary texts are helpful in learning more vocabulary in } \\
\text { the form of new words used in variant contexts }\end{array}$ & 4.800 & 5.00 & .7601 \\
$\begin{array}{l}\text { Literature develops my reading skills } \\
\text { Literary texts are helpful in recognizing grammatical }\end{array}$ & 4.633 & 5.00 & .8501 \\
$\begin{array}{l}\text { sentence build-up } \\
\begin{array}{l}\text { Exposure to literary texts enhances my different article } \\
\text { reading speed }\end{array}\end{array}$ & 4.533 & 5.00 & .7650 \\
\hline
\end{tabular}

The table implies a total mean value of 4.5 with a mode of 5 and standard deviation not exceeding 0.8 to indicate a strong majority of participants agree that literature, in general, enhances the development of competence in different areas of the English language. This positive view is mostly due to the richness of literary texts and their authenticity that provides learners with the language they probably encounter in real-life communications.

\section{First Research Question Chi-square Analysis}

Table 3: First Hypothesis Chi-square analysis

\begin{tabular}{|c|c|c|c|}
\hline Statements & Chi-Square & df & $\begin{array}{l}\text { Asymp. } \\
\text { Sig. }\end{array}$ \\
\hline $\begin{array}{l}\text { Literary texts are helpful in learning more } \\
\text { vocabulary in the form of new words used in } \\
\text { variant contexts }\end{array}$ & 43.500 & 2 & .000 \\
\hline Literature develops my reading skills & 44.233 & 2 & .000 \\
\hline $\begin{array}{l}\text { Literary texts are helpful in recognizing } \\
\text { grammatical sentence build-up }\end{array}$ & 6.201 & 3 & .000 \\
\hline $\begin{array}{l}\text { Exposure to literary texts enhances my different } \\
\text { article reading speed }\end{array}$ & 28.133 & 2 & .045 \\
\hline
\end{tabular}

The table shows that the Chi-square values stand at 28.133, 6.201, 44.233 and 43.500, while the degree of freedom values stand at 2, 2, 3 and 2. All the standard significance values are below the 0.05 mark and stand at 0.045, 0.000, 0.000 and 0.000, which indicates the validity and acceptance of the hypothesis that the inclusion of 
literature in teaching a second/foreign language (English) positively impacts the learners' development of various skills of language.

\section{Second Research Question Validation}

Table 4: Second hypothesis percentage and frequencies

\begin{tabular}{llllll}
\hline Statements & $\begin{array}{l}\text { Strongly } \\
\text { Agree }\end{array}$ & Agree & Neutral & Disagree & $\begin{array}{l}\text { Strongly } \\
\text { Disagree }\end{array}$ \\
\hline $\begin{array}{l}\text { Literary materials enhance } \\
\text { my cultural knowledge }\end{array}$ & 16 & 10 & 4 & - & - \\
$\begin{array}{l}\text { Literature develops an } \\
\text { understanding of different }\end{array}$ & 15 & 12 & 3 & - & - \\
$\begin{array}{l}\text { ideas and thoughts } \\
\text { Reading field-specific }\end{array}$ & $50.0 \%$ & $40.0 \%$ & $10.0 \%$ & - & - \\
$\begin{array}{l}\text { vocabulary literary texts is } \\
\text { challenging }\end{array}$ & 21 & 4 & 3 & - & 2 \\
& $70.0 \%$ & $13.3 \%$ & $10.0 \%$ & - & $6.7 \%$ \\
$\begin{array}{l}\text { A correlation exists between } \\
\text { text type and its intelligibility }\end{array}$ & 21 & 8 & - & - & 1 \\
& $70.0 \%$ & $26.7 \%$ & - & - & $3.3 \%$ \\
\hline
\end{tabular}

From the table, it can be seen that 16 of the participants strongly agree (53.3\%), 10 agree $(33.3 \%)$, and 4 remain neutral $(13.3 \%)$ that literary texts can strengthen cultural knowledge. It also shows that 15 strongly agree (50.0\%), 12 agree (40.0), and 3 remain neutral (10.0) that literature enhances the understanding of varied ideas and thoughts. Similarly, 21 respondents strongly agree (70.0\%), 4 agree (13.3\%), 3 remain neutral $(10.0 \%)$ as 2 strongly disagree $(6.7 \%)$ that use of literary texts become problematic when authors overuse field-specific vocabulary. It further shows that 21 respondents strongly agree (70.0\%), 8 agree $(26.7 \%)$, and 1 strongly disagrees $(3.3 \%)$ that there exists a relationship between text type and its general intelligibility.

\section{Second Research Question Descriptive Analysis}


Table 5: Second hypothesis descriptive analysis

\begin{tabular}{llll}
\hline Statements & Mean & Mode & Std. Deviation \\
\hline Literary materials enhance my cultural knowledge & 4.3000 & 5 & .73279 \\
$\begin{array}{l}\text { Literature develops an understanding of different } \\
\text { ideas and thoughts }\end{array}$ & 4.5000 & 5 & .6976 \\
$\begin{array}{l}\text { Reading field-specific vocabulary literary texts is } \\
\text { challenging }\end{array}$ & 4.5000 & 5 & .1 .0319 \\
$\begin{array}{l}\text { A correlation exists between text type and its } \\
\text { intelligibility }\end{array}$ & 4.5000 & 5 & .8103 \\
\end{tabular}

The total mean value is at 4.45 , the mode at 5 , and the standard deviation well below 1 to indicate that most of the participants strongly agree that literature reflects the authorial cultural background and ideology for variant text understanding. However, it should be noted texts should be selected according to the proficiency level of learners.

\section{Second Research Question Chi-square analysis}

Table 6: Second hypothesis Chi-square analysis

\begin{tabular}{|c|c|c|c|}
\hline Statements & Chi-Square & df & Asymp. Sig. \\
\hline Literary materials enhance my cultural knowledge. & 7.125 & 2 & .028 \\
\hline $\begin{array}{l}\text { Literature develops an understanding of different } \\
\text { ideas and thoughts }\end{array}$ & 7.750 & 2 & .021 \\
\hline $\begin{array}{l}\text { Reading field-specific vocabulary literary texts is } \\
\text { challenging }\end{array}$ & 33.741 & 3 & .000 \\
\hline $\begin{array}{l}\text { A correlation exists between text type and its } \\
\text { intelligibility }\end{array}$ & 21.200 & 2 & .000 \\
\hline
\end{tabular}

It is shown that $21.200,33.741,7.750$ and 7.125 are the Chi-square values, with the freedom degree values being 2, 3,2 and 2. All the standard significance values are below the 0.05 mark and stand at $0.280,0.210,0.000$, and 0.000 , indicating the validity and acceptance of the hypothesis that literary texts reflect the authorial cultural background and ideology for variant text understanding. 


\section{Third Research Question Validation}

Table 7: Third hypothesis percentage and frequencies

\begin{tabular}{|c|c|c|c|c|c|}
\hline Statements & $\begin{array}{l}\text { Strongly } \\
\text { Agree }\end{array}$ & Agree & Neutral & Disagree & $\begin{array}{l}\text { Strongly } \\
\text { Disagree }\end{array}$ \\
\hline \multirow{2}{*}{$\begin{array}{l}\text { Different sentence types are } \\
\text { used in different literary text } \\
\text { types for reader benefit. }\end{array}$} & 12 & 14 & 3 & 1 & - \\
\hline & $40.0 \%$ & $46.7 \%$ & $10.0 \%$ & $3.3 \%$ & - \\
\hline \multirow{2}{*}{$\begin{array}{l}\text { Different syntactical forms } \\
\text { enhance further reading }\end{array}$} & 12 & 14 & 4 & - & - \\
\hline & $40.0 \%$ & $46.7 \%$ & $13.3 \%$ & - & - \\
\hline \multirow{2}{*}{$\begin{array}{l}\text { Literary texts enhance } \\
\text { meaning and semantic } \\
\text { understanding }\end{array}$} & 17 & 11 & 1 & - & 1 \\
\hline & $56.7 \%$ & $36.7 \%$ & $3.3 \%$ & - & $3.3 \%$ \\
\hline \multirow{2}{*}{$\begin{array}{l}\text { Literature enhances thought } \\
\text { and idea creation }\end{array}$} & 18 & 10 & 1 & - & 1 \\
\hline & $60.0 \%$ & $33.3 \%$ & $3.3 \%$ & - & $3.3 \%$ \\
\hline
\end{tabular}

The table justifies that 12 respondents strongly agree (40.0\%), 14 agree (46.7\%), 3 are neutral $(10.0 \%)$, and 1 disagrees (3.3\%) with the assertion that different sentence types are used in different literary texts which improve reading comprehension. 15 participants $(50.0 \%), 12$ agree $(40.0 \%)$, and 3 remain neutral $(10.0 \%)$ regarding the statement that syntactical form differences enhance reading. Similarly, 17 respondents strongly agree (56.7\%), 11 agree (36.7\%), 1 remains neutral (3.3\%), and 1 strongly disagrees (3.3\%) that literary texts positively improve meaning and semantic understanding. Lastly, 18 respondents strongly agree (60.0\%), 10 agree (33.3\%), 1 remains neutral (3.3\%), and 1 strongly disagrees (3.3\%) that such texts enhance thought and idea creation.

\section{Third Research Question Descriptive Analysis}

Table 8: Third hypothesis descriptive analysis

\begin{tabular}{|c|c|c|c|}
\hline Statements & Mean & Mode & $\begin{array}{l}\text { Std. } \\
\text { Deviation }\end{array}$ \\
\hline $\begin{array}{l}\text { Different sentence types are used in different text } \\
\text { types for reader benefit }\end{array}$ & 4.3222 & 4 & .73279 \\
\hline Different syntactical forms enhance further reading & 4. & 5 & .8472 \\
\hline $\begin{array}{l}\text { Literary texts enhance meaning and semantic } \\
\text { understanding }\end{array}$ & 4.5000 & 4 & .6976 \\
\hline Literature enhances thought and idea creation & 4. & 5 & .8503 \\
\hline
\end{tabular}


The total mean value is at 4.4 , the mode at 5 and 4 , and the standard deviation at 0.79 to indicate that a majority of the participants strongly agree that the inclusion of literature helps respondents recognize different sentence types and the improvement of thought and creativity.

\section{Third Research Question Chi-square Analysis}

Table 9: Third hypothesis Chi-square analysis

\begin{tabular}{llll}
\hline Statements & Chi-Square & df & $\begin{array}{l}\text { Asymp. } \\
\text { Sig. }\end{array}$ \\
\hline $\begin{array}{l}\text { Different sentence types are used in different text } \\
\text { types for reader benefit }\end{array}$ & 15.979 & 2 & .000 \\
$\begin{array}{l}\text { Different syntactical forms enhance further reading } \\
\text { Literary texts enhance meaning and semantic }\end{array}$ & 6.750 & 2 & .001 \\
$\begin{array}{l}\text { understanding } \\
\text { Literature enhances thought and idea creation }\end{array}$ & 23.200 & 3 & .061 \\
\hline
\end{tabular}

It is shown that $23.200,32.447,6.750$ and 15.979 are the Chi-square values, with the freedom degree values being 2, 2, 2 and 3 . All the standard significance values are below the 0.05 mark and stand at $0.000,0.000,0.001$, and 0.061 , indicating the validity and acceptance of the hypothesis that literature may help learners recognize different sentence pattern types and creativity.

\section{Qualitative Findings}

This section undertakes an analysis of the data collected qualitatively using openended questions. Similar to the quantitative findings, the qualitative results revealed that the overwhelming majority of the participants ( 9 out of 10) showed a positive attitude towards literary texts in learning English. This positive perspective is attributed to several reasons. The results indicated that literary materials critically enhance competence in different areas of the English language. That is to say, the strong majority ( 8 out of 10) of the respondents believe that the inclusion of literary texts in teaching English would help them in developing the four language skills. To illustrate this: Participant 5 stated: "look, I firmly believe that if teachers use literary texts while teaching a second or even foreign language (in our case English), this would definitely help us to better develop the language skills". In addition to that, another participant mentioned, Participant 8: "You know, following the tedious and standard books only, I think, would not prepare us to be able to establish meaningful communications. In other words, if teachers expose us to literary materials here and there that would, for sure, help us to improve our language skills, especially communicate skills." 
Culture and language are inseparable. Therefore, in teaching a second language, cultural competence should be taught how attention is given to linguistic competence. Regarding this, the findings also indicated that all the participants (10 out of 10) consider literary texts a fundamental and rich source for enhancing cultural knowledge. Participant 10 stated: "I think literary texts mirror a target language's culture. Such texts provide us many samples and examples related to the culture of the target language. Thus, via this we can enrich our knowledge about TL culture." Similarly, another participant emphasized the importance of literature in the portrayal of culture. Participant 1: "Let me start with saying language is culture and learning a language is learning the culture of the language. Undoubtedly, literature is the encyclopaedia of the culture of each nation. So that, I would say literary texts are the best and only significant source that would help us to master this significant knowledge."

A bulk of research has witnessed the reputation of motivation in second/foreign language teaching and learning. Regarding this, all the participants (10 out of 10) agreed that countering literary texts in the classes trigger and increase their motivation, resulting in developing more interest in the learning. Participant 4 argued: literary texts, especially short stories, are obviously exciting to learners who are primarily curious about how stories unfold or end. As such, a good selection and appropriate support will motivate us in the learning process..." In the same line, participants 3,7 showed the same perspective: "I think it is very useful and I do enjoy literature and also practice other language skills through literary texts. For example, I depend on literary texts to improve my reading and writing skills. Following the reading, writing books to me is boring, I can say, but literature adds interest..."

\section{Conclusion}

The conventional teaching method in the FL classes has been and continues to be through certain standard course books. An apparently current approach to second language teaching is to include literature in the EFL class in order to get more desirable outcomes and for learners to attain near-native competency, which is the primary goal for achieving a second language across the world. These materials would lead learners to think that language is composed of fixed expressions and transactions that they have to master to meet the exam and academic requirements. This mindset hinders learners from viewing language learning as a lifelong undertaking process and undergoing what language contains beyond the visible part, such as cultural norms. Therefore, the research objective was mainly twofold. Firstly, the study attempted to investigate Kurdish EFL students' attitudes and opinions towards the use and the inclusion of literary texts in English language teaching and secondly, to unveil in what ways such texts would help to assist the learning process as well as what areas of language shall be best developed through literary materials. The results indicated that learners have a positive attitude towards literary texts in general. The overwhelming majority of the students argued that the inclusion of literary texts would help them to not only master the linguistic competence, but the functional aspects of language as well which is 
significant for an appropriate and correct communication. The data further showed that exposure to such materials enhances students' cultural knowledge and awareness.

\section{Pedagogical Recommendations}

Owing to the findings, the following recommendations can be made:

i) In English classes, teachers shall re-consider their syllabi to include more literary texts.

ii) Since literature by nature is not easy to understand, popular literary texts can be edited for simplification for EFL learners in language teaching classes.

iii) Teaching a second/ foreign language in isolation from its cultural norms would not succeed learners. Thus, to teach culture alongside linguistic competence, literary texts are the most effective materials.

\section{References}

Ali, F.S. (2021). Overlap and repair of turn- taking system during collaborative oral peer-feedback in an EFL writing course. International Journal of Social Sciences \& Educational Studies, 8(2), 128-134.

Altun, M., \& Sabah, R. (2020). The effect of cooperative learning strategies in the enhancement of EFL learners' speaking skills. Asian EFL Journal, 27(2), 144171.

Altun, M. (2020). The role of storytelling on students speaking skills. Journal of Critical Reviews, 7(16), 2390-2394.

Barzani, S. H. H. (2020). The perceptions of EFL teachers and students on the use of short stories to enhance reading comprehension. Asian EFL Journal 27(3.1), 325-341.

Barzani, S.H.H., \& Rayan J. J. (2021). Students' perceptions towards online education during COVID-19 pandemic: An empirical study. International Journal of Social Sciences \& Educational Studies, 8(2), 28-38.

Doi: 10.23918/ijsses.v8i2p28

Bloom, B. S. (1956). Taxonomy of educational objectives. United States.

Collie, J., \& Stephen S. (2005). Literature in the language classroom. U.K: Cambridge University Press.

Davis, J. C., \& Palmer, J. (1992). A strategy for using children's literature to extend the social studies curriculum. The Social Studies, 83(3), 125-128.

Elhaj, A. I. (2017). The role of short stories in developing reading skill for EFL learners. Unpublished MA thesis. Sudan University of Science and Technology College of Graduate Studies.

Erkaya, O. (2003). Benefits of using short stories in the EFL context. Asian -EFLJournal.1- $13 . \quad$ Retrieved from http://www.asian-efljournal.com/pta_nov_ore.pdf

Fuad, H. A., \& Ulker, V. (2020). The effect of inquiry-based approach on development of reading and writing skills of a university EFL students. Asian EFL Journal, 27(2.3), 84-100.

Gerrard-Morris, A., Taylor, H., Yeates, K., Walz, N., Stancin, T., Minich, N., \& Wade, S. (2010). Cognitive development after traumatic brain injury in young 
children. Journal of the International Neuropsychological Society, 16(1), 157168. Doi:10.1017/S1355617709991135

Khaki, N. (2014). Improving reading comprehension in a foreign language: Strategic reader. Reading Matrix: An International Online Journal, 14, (2), 186-200.

Khatib, M., \& Nasrollahi, A. (2012). Enhancing reading comprehension through short stories in Iranian EFL learners. Academy Publisher.

Kilfoil, W. R., \& Van, W. C. (2003). Learn 2 teach: English language teaching in a multilingual context. Pretoria: Van Schaik Academic.

Mahmoud, M. (2015). Culture and English Language Teaching in the Arab World. Adult Learning. 26(2), 66-72. Retrieved from https://journals.sagepub.com/doi/abs/10.1177/1045159515573020

Murdoch, G. (2002). Exploiting well-known short stories for language skills development. IATEFL LCS SIG Newsletter, 23.

Newton, J. M., Ferris, D. R., Goh, C. C. M., Grabe, W., Stoller, F. L., \& Vandergrift, L. (2018). Teaching English to second language learners in academic contexts: Reading, writing, listening, and speaking.

O'Connell, F. (2009). A Brief History and Theory. In (Ed.) Brit Lit: Using literature in ELT classrooms. London: British Council. Retrieved from http://www.teachingenglish.org.uk/try /resources/britlit

Omid, P., \& Nasibeh, K. (2013). Teaching reading comprehension through short stories in advance classes. Asian Journal of Social Sciences \& Humanities, 2, 52-60.

Pardede, P. (2011). Using short stories to teach language skills. Journal of English Teaching, (1), 14-27.

Pokharel, P. (2018). Learning to read and reading to learn in English. Journal of NELTA Surkhet, 5, 75-81. https://doi.org/10.3126/jns.v5i0.19490

Rew, S., \& Moon, Y. (2013). The effects of using English drama on the learning of target expressions for primary school students. The Journal of Asia Tefl, 10(4), 215- 239.

Rubin, D. (1993). A practical approach to teaching reading. Boston, MA: Allyn and Bacon.

Sultan, A., Nafi, J., Qabaja, Z., \& Al-abed, S. (2018). The effect of using short stories on the development of 5th graders' reading comprehension skills In Hebron District. International Journal of English Language Teaching, 1-27.

Zirak, H. C. K. (2021) Embodied learning implementation in EFL classroom: A qualitative study. International Journal of Social Sciences \& Educational Studies, 8(1), 51-58. Doi: 10.23918/ijsses.v8i1p51 